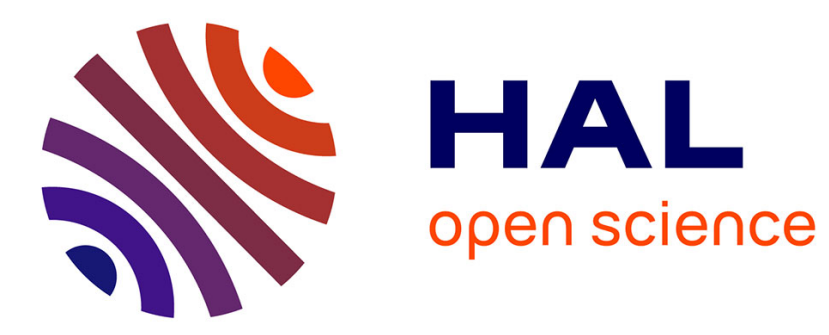

\title{
Chirality transfer in a cage controls the clockwise/anticlockwise propeller arrangement of the tris(2-pyridylmethyl)amine ligand
}

Gege Qiu, Cédric Colomban, Nicolas Vanthuyne, Michel Giorgi, Alexandre Martinez

\section{To cite this version:}

Gege Qiu, Cédric Colomban, Nicolas Vanthuyne, Michel Giorgi, Alexandre Martinez. Chirality transfer in a cage controls the clockwise/anticlockwise propeller arrangement of the tris(2-pyridylmethyl)amine ligand. Chemical Communications, 2019, 55 (94), pp.14158-14161. $10.1039 / \mathrm{c} 9 \mathrm{cc} 07244 \mathrm{f}$. hal-02368870

\section{HAL Id: hal-02368870 https://hal.science/hal-02368870}

Submitted on 23 Mar 2020

HAL is a multi-disciplinary open access archive for the deposit and dissemination of scientific research documents, whether they are published or not. The documents may come from teaching and research institutions in France or abroad, or from public or private research centers.
L'archive ouverte pluridisciplinaire HAL, est destinée au dépôt et à la diffusion de documents scientifiques de niveau recherche, publiés ou non, émanant des établissements d'enseignement et de recherche français ou étrangers, des laboratoires publics ou privés. 


\title{
Chirality transfer in a cage controls the clockwise/anticlockwise propeller arrangement of the tris(2-pyridylmethyl)amine ligand
}

\author{
Qiu, G. G., Colomban, C.,Vanthuyne, N., Giorgi, M., Martinez, A.
}

\begin{abstract}
Predictable control of the propeller arrangement of the tris(2-pyridylmethyl)amine (TPA) ligand was achieved through the preparation of the smallest hemicryptophane 1 . This newly designed cage displays a chirality transfer from its northern unit to the TPA ligand. 1 can coordinate $\mathrm{Cu}(1)$, yielding a rare $\mathrm{T}$-shaped complex with controlled helicity of the TPA-Cu(I) core.
\end{abstract}

The tris(2-pyridylmethyl)amine (TPA) ligand has been widely reported as a convenient and efficient scaffold for the development of metal-based complexes, catalysts and sensors. In particular, structural and functional models of iron(II) ${ }^{1}$ and copper(I) ${ }^{2}$ mono-oxygenases, based on the TPA unit, have been developed. TPA derivatives have also been involved in the preparation of stereodynamic metal complexes applied in chiral sensing and enantiomeric excess determination. ${ }^{3}$ Furthermore, this tripodal ligand has recently aroused growing interest in the field of supramolecular architectures. It has been indeed successfully incorporated into supramolecular cages, aiming at developing switchable dynamic architectures, ${ }^{4}$ or at providing new platforms for coordination, and host-guest chemistry in confined spaces. ${ }^{5}$

Due to its broad interest, versatility, and conformational dynamic nature, the control of the chirality of this $C_{3}$ symmetrical ligand is highly desirable. Because of the propeller-like arrangement of its pyridine units, the TPA ligand rapidly interconverts between two enantiomeric conformations. Controlling the sense of the pyridine twist is therefore key to access new organic chiral architectures with potential application in sensing biological molecules, enantioselective catalysis, or preparation of optically pure materials. The control of the dynamics of the propeller arrangement of the TPA ligand (clockwise or anticlockwise) has been initially achieved through synthetic modification of the TPA core such as incorporation of an alkyl group at one of the benzylic positions. ${ }^{6}$ Such modified ligands result in a shift of the equilibrium toward one of the two (right or left-handed) stereoisomers. More recently, Badjić and coworkers reported an elegant strategy based on the supramolecular functionalization of a cationic TPA derivative with an anionic $C_{3}$ symmetrical concave basket. ${ }^{7}$ The static chirality of the basket results in the exclusive formation of a left-handed Zn-TPA supramolecular complex via intermolecular ionic contact. Furthermore, very lately, a length-dependent inversion of the TPA helicity upon guest-binding in a supramolecular cage has been described. ${ }^{8}$

We present herein a new approach to build TPA-based architectures displaying a predictable and controlled propellerlike arrangement of the pyridines through its capping with a chiral $C_{3}$ symmetrical unit.

In our lab we recently incorporated a TPA ligand into an optically pure hemicryptophane organic cage $\mathbf{H m}$-Ph-TPA (Fig. 1a). ${ }^{9} \mathbf{H m}-\mathbf{P h}$ TPA displays a chiral $C_{3}$ symmetrical cyclotriveratrylene (CTV) unit covalently linked to the TPA moiety through phenyl spacers. Its corresponding iron(II) complex was described as an efficient bioinspired catalyst for the oxidation of methane in confined space. ${ }^{10}$

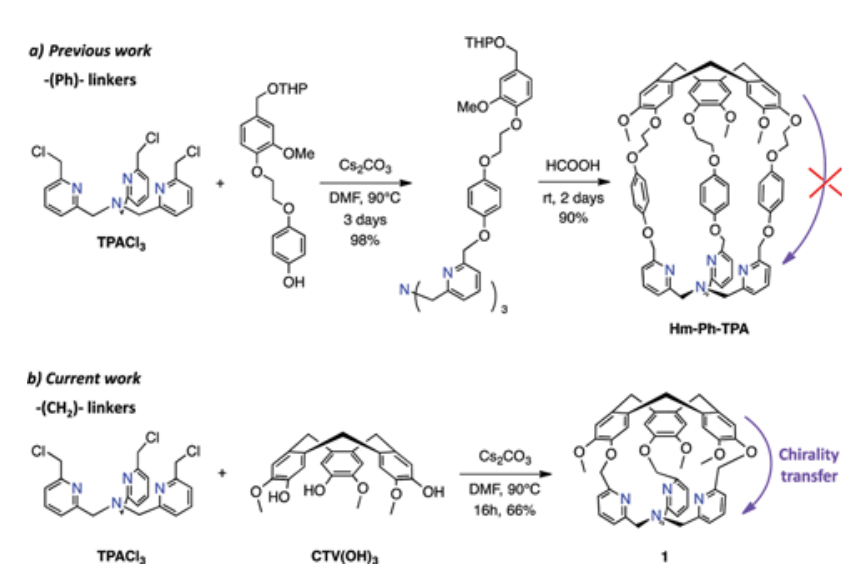

Fig. 1 (a) Previously reported synthesis of hemicryptophane $\mathrm{Hm}$-Ph-TPA. (b) "1 +1 coupling" strategy used for the synthesis of 1 . 
A careful look at its XRD structure indicates the formation of a triplestranded helical arrangement of the phenyl linkers dictated by the chirality of the CTV unit ( $P$ - or $M$-configuration). However, no orientation of the three southern pyridines could be observed (see Fig. S12 and S13, ESI $\dagger$ ). Clearly, in Hm-Ph-TPA, the chiral CTV is situated too far from the southern TPA unit to induce any chirality transfer. On this basis, we envisioned that the building of hemicryptophane displaying shorter linkers might result in an efficient chirality transfer from the CTV to the TPA unit. We therefore design a new hemicryptophane $\mathbf{1}$, which displays a CTV unit linked to a TPA moiety by simple methylene $-\mathrm{CH}_{2}$ - linkers, representing the smallest hemicryptophane ever reported. ${ }^{11} \mathbf{1}$ was obtained in a $66 \%$ yield via the direct coupling of the CTV intermediate $\mathbf{C T V}(\mathbf{O H})_{3}$ and the TPA-trichloride precursor $\mathbf{T P A C l}_{\mathbf{3}}$ (Fig. 1b). Compared to Hm-Ph-TPA, which was obtained following a "template approach", ${ }^{11}$ the one step synthesis of $\mathbf{1}$ represents an alternative and more straightforward access to TPA-based capsules. Due to the chiral nature of its northern CTV unit, $\mathbf{1}$ is obtained as a racemate $( \pm)-\mathbf{1}$ that could be optically resolved using chiral HPLC (see the ESI + ). Enantiopure $(-)-(M)-\mathbf{1}$ and $(+)-(P)-\mathbf{1}$ hosts have been indeed efficiently separated with ee values $>99.5 \%$ and their absolute configuration determined through electronic circular dichroism (ECD) analysis (Fig. 2 and Fig. S1, ESI $\dagger$ ). ${ }^{12}$

Single crystals of $\mathbf{1}$, suitable for X-ray diffraction, were obtained by slow diffusion of $\mathrm{Et}_{2} \mathrm{O}$ to a solution of the cage in $\mathrm{CH}_{2} \mathrm{Cl}_{2} .1$ crystallizes with an asymmetric unit containing four molecules with two of each enantiomers corresponding to CTV with $M$ - and $P$-configurations (Fig. S2, ESI $\dagger$ ). The resulting XRD structure confirms the functionalization of the TPA ligand by the bowl-shaped CTV unit, which describes a well-defined cavity. Contrary to $\mathbf{H m}-\mathbf{P h}$-TPA, no $\mathrm{CH}_{2} \mathrm{Cl}_{2}$ molecule is observed inside the cavity of $\mathbf{1}$, which appears to be too small for encapsulation of exogenous organic solvent molecules. Instead, one of the three methylene $-\mathrm{CH}_{2}-\mathrm{N}$ groups of the TPA unit resides inside the hydrophobic cavity of $\mathbf{1}$ with the two $\mathrm{C}-\mathrm{H}$ bonds pointing toward the inner space. The two other $-\mathrm{CH}_{2}-\mathrm{N}$ groups point outward (Fig. 2). Such "self-encapsulation" of one $-\mathrm{CH}_{2}-\mathrm{N}$ group therefore results in a $C_{1}$ symmetrical conformation of 1. Interestingly, a remarkable propeller-like arrangement of the three pyridines of the southern unit, imposed by the chirality of the northern CTV, is clearly observed. The hemicryptophane $(M)-\mathbf{1}$ bearing a $M$-CTV unit indeed imposes a left-handed $(M)$ propellerlike arrangement of the TPA's pyridines while the $(P)-\mathbf{1}$ counterpart displays a right-handed $(P)$ helicity (Fig. 2). Importantly, such a propeller-like arrangement of the pyridine units could not be observed in the previously reported hemicryptophane Hm-Ph-TPA. In solution, the ${ }^{1} \mathrm{H}$ NMR spectrum of $\mathbf{1}$ displays identical, sharp and well-defined signals for the protons belonging to the pyridine $\left(\mathrm{H}_{\mathrm{b}}, \mathrm{H}_{\mathrm{c}}\right.$, and $\left.\mathrm{H}_{\mathrm{d}}\right)$, the $-\mathrm{CH}_{2}$ - linkers $\left(\mathrm{H}_{\mathrm{e}, \mathrm{e}^{\prime}}\right)$ and CTV units $\left(\mathrm{H}_{\mathrm{h}}, \mathrm{H}_{\mathrm{g}}, \mathrm{H}_{\mathrm{f}}\right.$, and $\left.\mathrm{H}_{\mathrm{i}, \mathrm{i}^{\prime}}\right)$, indicating that 1 presents, on average, a $C_{3}$ symmetrical structure in $\mathrm{CDCl}_{3}$, at room temperature (Fig. 3a). The assignment of these resonances was achieved through 2D-NMR experiments (see the ESI $\dagger$ ). Contrary to Hm-Ph-TPA, ${ }^{9,10}$ and other reported TPA-based cages, ${ }^{4} \mathbf{1}$ displays clearly distinct signals for the methylene protons $\left(-\mathrm{CH}_{2}-\mathrm{N}\right)$ at the alpha position of the tertiary amine $\left(\mathrm{H}_{\mathrm{a} / \mathrm{a}^{\prime}}, \Delta \delta=0.66 \mathrm{ppm}\right)$ revealing their diastereotopic
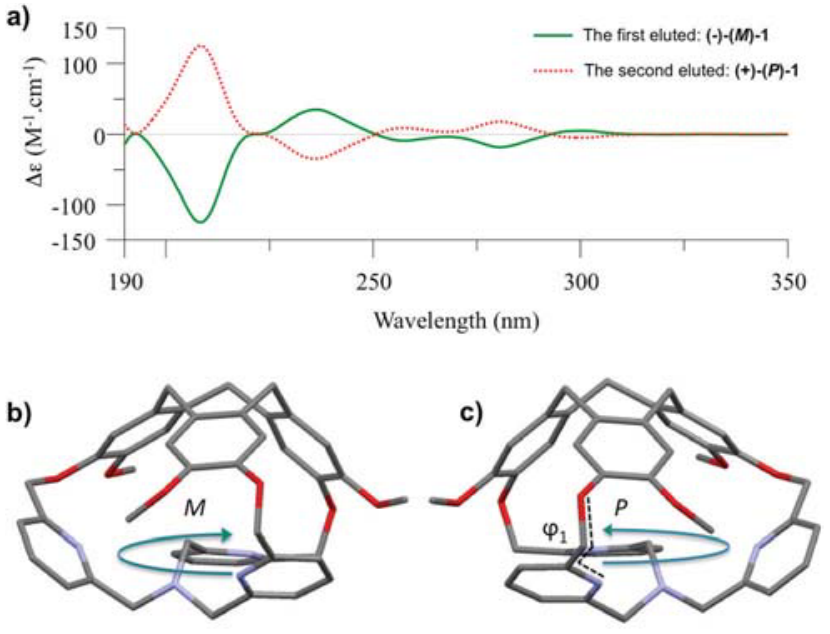

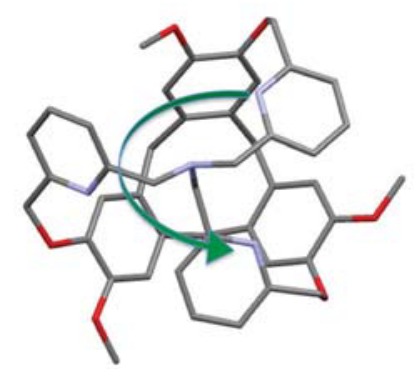

(M)-1

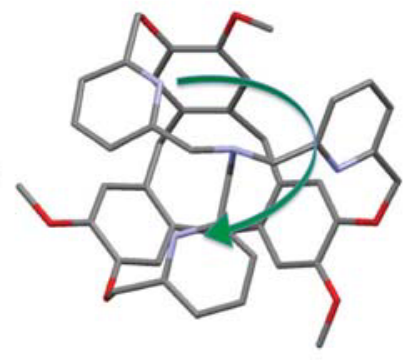

$(P)-1$
Fig. 2 (a) ECD spectra of (-)-(M)-1 (green) and (+)-(P)-1 (red), in $\mathrm{CH}_{3} \mathrm{CN}$ at 298 K. Diagram of the X-ray crystal structure of $( \pm)-\mathbf{1}$ : (b) $(M)-\mathbf{1}$ and $(\mathrm{c})(P)-\mathbf{1}$. Green arrow: orientation of the arrangement of the pyridines. Twists of the pyridines, reflected by the $\mathrm{O}-\mathrm{C}-\mathrm{C}-\mathrm{N}$ torsion $\varphi(\varphi=(\varphi 1+\varphi 2+\varphi 3) / 3)$, have been estimated from these structures: $\varphi=-68.6^{\circ}$ for $(M)-1$ and $\varphi=+68.6^{\circ}$ for $(P)-1\left((M)-1: \varphi 1=-8.5^{\circ}, \varphi 2=-106.4^{\circ}, \varphi 3=-90.75^{\circ}\right.$, and $(P)-1: \varphi 1=+8.5^{\circ}$, $\left.\varphi 2=+106.4^{\circ}, \varphi 3=+90.75^{\circ}\right)$.

character. It should be noted that the highly symmetrical ${ }^{1} \mathrm{H}$ NMR spectrum observed for 1 in solution, at $298 \mathrm{~K}$, contrasts with the $C_{1}$ symmetrical structure observed in the solid-state. This is easily explained by a fast conformational exchange between the inward and outward orientations of the $-\mathrm{CH}_{2}-\mathrm{N}$ methylene groups at $298 \mathrm{~K}$ in solution. Interestingly, the 2D-NMR NOESY experiment reveals through-space correlations between methylene proton $\mathrm{H}_{\mathrm{a}, \mathrm{a}^{\prime}}$ and aromatic protons $\mathrm{H}_{\mathrm{f}, \mathrm{g}}$ belonging to the northern CTV unit as well as between signals corresponding to the $\mathrm{H}_{\mathrm{b}}, \mathrm{H}_{\mathrm{c}}$, and $\mathrm{H}_{\mathrm{d}}$ protons of the pyridines and the one corresponding to the $-\mathrm{OCH}_{3}$ of the CTV unit, $\mathrm{H}_{\mathrm{h}}$ (Fig. S3, ESI $\dagger$ ). Such through-space correlations attest for the self-inclusion of one methylene $-\mathrm{CH}_{2}-\mathrm{N}$ group (Fig. S3, ESI $\dagger$ ), and therefore confirm that the $C_{1}$ symmetrical form of $\mathbf{1}$ (observed in the solid state) is also present in solution. Variable temperature (VT) ${ }^{1} \mathrm{H}$ NMR analysis of $\mathbf{1}$ indicates a particularly fast motion as broadening but no complete decoalescence of the signals was observed in the 298-220 K temperature range (Fig. S5, ESI + ).

Could this dynamic behaviour be slowed down to observe the $C_{1}$ symmetrical conformation of 1 by VT ${ }^{1} \mathrm{H}$ NMR studies? Badjic and co-workers have recently shown that the protonation of the tertiary amine of the covalent TPA-based capsule with $\mathrm{HCl}$ results in less dynamic and more preorganized receptors. In this vein, we assumed that the protonation of the TPA moiety 

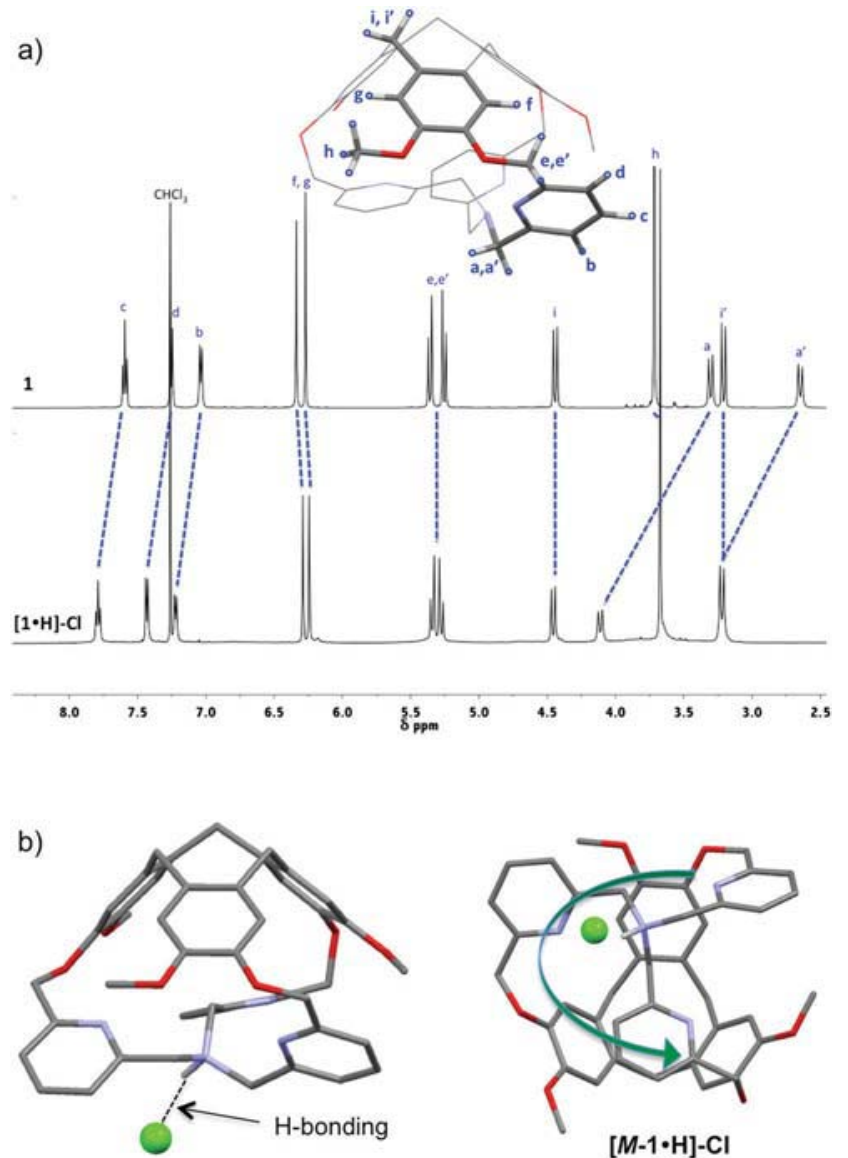

Fig. 3 (a) Partial ${ }^{1} \mathrm{H}$ NMR spectra $\left(500 \mathrm{MHz} \mathrm{CDCl}_{3}, 298 \mathrm{~K}\right.$ ) of 1 (top) and [1.H]-Cl (bottom). (b) Side (left) and south (right) views of the X-ray crystal structure of the protonated capsule $[(\mathrm{M})-\mathbf{1} \cdot \mathbf{H}]-\mathrm{Cl}$. Only the hydrogen atom belonging to the protonated tertiary amine has been included for clarity.

of 1 might slow down the dynamic $-\mathrm{CH}_{2}-\mathrm{N}$ exchange motion observed from 298 to $220 \mathrm{~K}$. Our attempts lead to success as the VT-NMR study of the protonated racemate $[\mathbf{1} \cdot \mathbf{H}]-\mathbf{C l}$ (see the ESI $\dagger$ for preparation) reveals a progressive appearance of a new set of signals, with more complex patterns, upon decreasing the temperature to $250-215 \mathrm{~K}$ (Fig. S7, ESI $\dagger$ ). Compared to the effective 3 -fold symmetry (on average) observed for $[\mathbf{1} \cdot \mathbf{H}]$-Cl at $298 \mathrm{~K}$, these new signals appear to be split, indicating a loss of the cage symmetry (Fig. S8, ESI $\dagger$ ). Clearly, at lower temperature, the $-\mathrm{CH}_{2}-\mathrm{N}$ exchange becomes slower on the NMR time scale allowing for the observation of the $C_{1}$ symmetrical configuration of $[\mathbf{1} \cdot \mathbf{H}]$-Cl. Indeed, alike $\mathbf{1}$, the self-encapsulation of one methylene $-\mathrm{CH}_{2}-\mathrm{N}$ group in the hydrophobic cavity of $[\mathbf{1} \cdot \mathbf{H}]-\mathbf{C l}$ was observed in its XRD structure (Fig. 3b).

Importantly, this structure confirms a propeller-like organization of the three pyridines of the TPA unit that is imposed by the chirality of the northern CTV. The hemicryptophane bearing a $M$-CTV leads to the anticlockwise propeller-like arrangement of the TPA (Fig. 3b), while the P-CTV induces the clockwise configuration (Fig. S9, ESI $\dagger$ ). Altogether, these results demonstrate that (i) the $C_{1}$ symmetrical form of $\mathbf{1}$ (observed in the solid state) is involved in the conformational exchange observed in solution and (ii) the chirality transfer from the CTV to the TPA unit is maintained in the protonated form of $\mathbf{1}$.

On this basis, we then explored the possibility of performing metal-complexation at the propeller-shaped TPA unit of $\mathbf{1}$. Such coordination might indeed result in (i) the breaking of the propeller-like arrangement of the pyridines or, more interestingly, (ii) the formation of a new kind of enantiopure metal complex with a controlled chirality at the TPA coordination unit. To demonstrate the ability of $\mathbf{1}$ to form metallo-complexes, we studied its complexation properties toward copper(I) chloride salt. Various $\mathrm{CuCl}$ complexes of TPA derivatives have been reported over the past decade as structural models for copper containing oxygenase enzymes, ${ }^{13}$ or atom transfer catalysts. ${ }^{14}$ Although dissociation of one pyridyl moiety has been reported for $\mathbf{C u}^{\mathbf{I}}(\mathbf{T P A})(\mathbf{C l})$ in solution, the corresponding solid state structures always displayed a pentacoordinated copper in an achiral trigonal-bipyramidal (TBP) coordination geometry. ${ }^{14 b}$ The $\mathbf{C u}^{\mathbf{I}}(\mathbf{1})(\mathbf{C l})$ complex, prepared by reacting 1 with 1 equivalent of copper(I) chloride in THF (see the ESI $\dagger$ ), affords single crystals suitable for X-ray diffraction (Fig. 4a). Interestingly, while the XRD structures of hemicryptophanes $\mathbf{1}$ and [1.H]-Cl displayed racemic crystals of co-crystallized $M$ - and $P$-enantiomers, $\mathbf{C u}^{\mathbf{I}}(\mathbf{1})(\mathbf{C l})$ affords an enantiopure crystal which solely displayed the $M$-enantiomer in its asymmetric unit. Remarkably, the left-handed $(M-)$ propeller-like configuration of the TPA, imposed by the $M$-CTV cap, remains unchanged upon binding of $\mathbf{C u C l}$. $\mathbf{C u}^{\mathbf{I}}(\mathbf{1})(\mathbf{C l})$ therefore displays a helical asymmetry dictated by the chirality of the northern CTV unit. The copper center in $\mathbf{C u}^{\mathbf{I}}(\mathbf{1})(\mathbf{C l})$ displays a highly unusual trigonal planar T-shaped coordination mode. A tri-coordinated mononuclear copper(I) center, in a distorted trigonal plane that comprises the tertiary amine, one pyridine, and one chlorine ion in trans to the pyridine ligand, is indeed observed (Fig. 4a). Cu-N bond lengths of $2.543 \AA$ and $1.939 \AA$
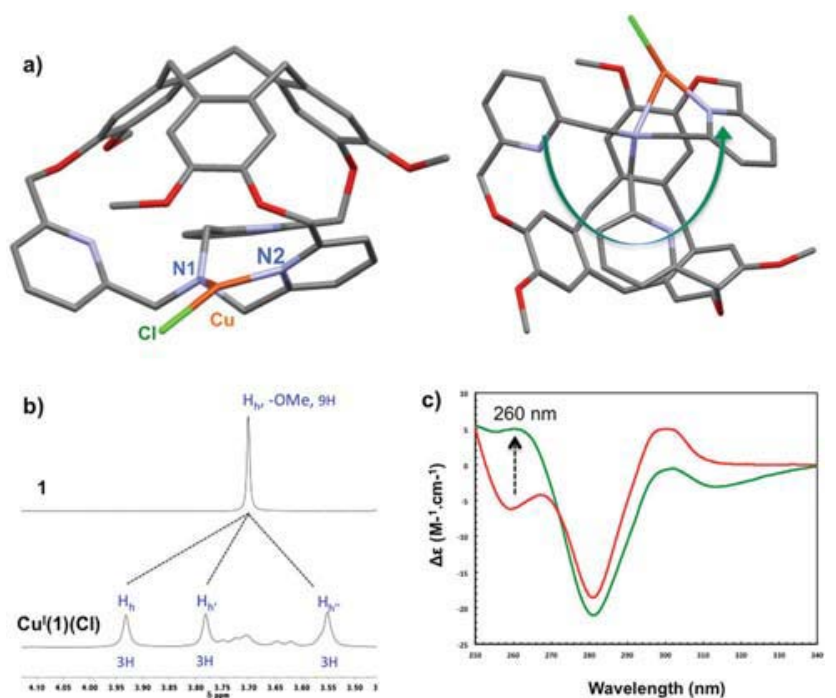

Fig. 4 (a) Side (left) and south (right) views of the X-ray crystal structure of the copper(I) complex (M)-Cu'(1)(Cl) displaying a M-CTV unit that imposes a $M$-propeller like arrangement of the TPA ligand. (b) Comparison of the partial ${ }^{1} \mathrm{H}$ NMR spectra $\left(500 \mathrm{MHz}, 260 \mathrm{~K}, \mathrm{CDCl}_{3}\right)$ of 1 and $\mathrm{Cu}^{\prime}(\mathbf{1})(\mathbf{C l})$. Comparison of the ECD spectra of the enantiopure $(M)-1$ ligand $(0.57 \mathrm{mM}$, red) and its corresponding $\mathrm{CuCl}$ complex (M)-Cu'(1)Cl $\left(0.51 \mathrm{mM}\right.$, green), in $\mathrm{CH}_{2} \mathrm{Cl}_{2}$ at $298 \mathrm{~K}$. 
were respectively found for the tertiary amine and the pyridine ligands, along with a $2.123 \AA$ long $\mathrm{Cu}-\mathrm{Cl}$ bond. Angles of $76^{\circ}, 112^{\circ}$ and $158^{\circ}$ were respectively found for $\mathrm{N}-\mathrm{Cu}-$ pyridine, $\mathrm{N}-\mathrm{Cu}-\mathrm{Cl}$ and pyridine- $\mathrm{Cu}-\mathrm{Cl}$, attesting for a distorted $\mathrm{T}$-shaped coordination mode. Importantly ${ }^{1} \mathrm{H}$ NMR analysis confirms that such a $C_{1}$ symmetrical structure is retained in solution (Fig. S10, ESI $\dagger$ ). Indeed, compared to the $C_{3}$ symmetrical (on average) spectra of $\mathbf{1}$, all signals of $\mathbf{C u}^{\mathbf{I}}(\mathbf{1})(\mathbf{C l})$ appear to be split, indicating a loss of the cage symmetry. For instance, the signals belonging to the $\mathrm{O}-\mathbf{C H}_{3}$ protons $\left(\mathrm{H}_{\mathrm{h}}\right)$, resonating as a single singlet in $\mathbf{1}$ (at $3.72 \mathrm{ppm}$ ), resonate as three distinct singlets in the case of $\mathbf{C u}^{\mathbf{I}}(\mathbf{1})(\mathbf{C l})$ (at 3.93, 3.78 and $3.55 \mathrm{ppm}$, Fig. 4b). To the best of our knowledge, the latter represents a totally unprecedented geometry for TPA-based copper(I) complexes. Such a coordination mode interestingly resembles that of some enzymatic active sites which display the $\mathrm{Cu}(\mathrm{I})$ center in a T-shaped geometry such as lytic polysaccharide monooxygenases (LPMOs) (displaying $\mathrm{Cu}(\mathrm{I})-\mathrm{N}(\mathrm{His})$ bond lengths of $1.9 \AA{ }^{15} .^{15}$

Finally, the enantiopure $(\boldsymbol{M})-\mathbf{C u}^{\mathbf{I}}(\mathbf{1})(\mathbf{C l})$ complex, prepared from the optically resolved $(M)-1$ ligand, was analysed by ECD spectroscopy. Compared to $(\boldsymbol{M})-\mathbf{1}$, the metallated $(\boldsymbol{M})-\mathbf{C} \mathbf{u}^{\mathbf{I}}(\mathbf{1})(\mathbf{C l})$ displayed a positive ECD couplet at $260 \mathrm{~nm}$ characteristic of the electronic $\pi-\pi^{*}$ transition of the TPA-metal chromophore. ${ }^{7,16}$ Along with XRD and ${ }^{1} \mathrm{H}-\mathrm{NMR}$ studies, the ECD analysis therefore confirms that the transfer of chirality from the CTV unit to the (TPA) $\mathrm{Cu}^{\mathrm{I}}(\mathrm{Cl})$ core occurs in both solid state and solution.

In conclusion, a novel variation in the TPA ligand is described, incorporating a chiral CTV unit that imposes and controls the propeller arrangement of the pyridine moieties. Such remote control of the TPA helicity was unambiguously demonstrated (through XRD analysis), in hemicryptophane $\mathbf{1}$ as well as in its protonated $[\mathbf{1} \cdot \mathbf{H}]$-Cl form. Importantly, the predictable chiral arrangement of the TPA ligand was maintained upon metallation of the hemicryptophane, leading to a novel chiral metal center with a highly unusual coordination mode in both solid state and solution. We envisioned that this new approach should find applications in the fields of asymmetric transformations and stereoselective sensing. Future work will be devoted to the use of such enantiopure metal-complexes as chiral catalysts and molecular receptors.

This work was supported by the ANR OH Risque grant (ANR14-OHRI-0015-03). We thank Mme R. Rosas for NMR assistance.

\section{Notes and references}

1 (a) M. Hee Lim, J. U. Rohde, A. Stubna, M. R. Bukowski, M. Costas, R. Y. N. Ho, E. Münck, W. Nam and L. Que, Jr., Proc. Natl. Acad. Sci. U. S. A., 2003, 100, 3665-3670; (b) M. Borrell and M. Costas, J. Am. Chem. Soc., 2017, 139, 12821-12829; (c) M. Borrell, E. Andris, R. Navrátil, J. Roithová and M. Costas, Nat. Commun., 2019, 10, 901.

2 (a) R. L. Peterson, R. A. Himes, H. Kotani, T. Suenobu, L. Tian, M. A. Siegler, E. I. Solomon, S. Fukuzumi and K. D. Karlin, J. Am. Chem. Soc., 2011, 133, 1702-1705; (b) I. Garcia-Bosch and M. A. Siegler, Angew. Chem., Int. Ed., 2016, 55, 12873-12876; (c) D. E. Diaz, D. A. Quist, A. E. Herzog, A. W. Schaefer, I. Kipouros, M. Bhadra, E. I. Solomon and K. D. Karlin, Angew. Chem., Int. Ed., 2019, DOI: 10.1002/anie.201908471.

3 (a) L. A. Joyce, M. S. Maynor, J. M. Dragna, G. M. da Cruz, V. M. Lynch, J. W. Canary and E. V. Anslyn, J. Am. Chem. Soc., 2011, 133, 13746-13752; (b) L. You, J. S. Berman and E. V. Anslyn, Nat. Chem., 2011, 3, 943; (c) H. H. Jo, R. Edupuganti, L. You, K. N. Dalby and E. V. Anslyn, Chem. Sci., 2015, 6, 158-164; (d) E. Badetti, K. Wurst, G. Licini and C. Zonta, Chem. - Eur. J., 2016, 22, 6515-6518; (e) R. Berardozzi, E. Badetti, N. A. Carmo dos Santos, K. Wurst, G. Licini, G. Pescitelli, C. Zonta and L. Di Bari, Chem. Commun., 2016, 52, 8428-8431.

4 L. Zhiquan, H. Xie, S. E. Border, J. Gallucci, R. Z. Pavlović and J. D. Badjić, J. Am. Chem. Soc., 2018, 140, 11091-11100.

5 (a) C. Bravin, E. Badetti, F. A. Scaramuzzo, G. Licini and C. Zonta, J. Am. Chem. Soc., 2017, 139, 6456-6460; (b) N. Le Poul, B. Colasson, G. Thiabaud, D. Jeanne Dit Fouque, C. Iacobucci, A. Memboeuf, B. Douziech, J. Rezáč, T. Prangé, A. de la Lande, O. Reinaud and Y. Le Mest, Chem. Sci., 2018, 9, 8282-8290.

6 J. W. Canary, C. S. Allen, J. M. Castagnetto and Y. Wang, J. Am. Chem. Soc., 1995, 177, 8484-8485.

7 L. Zhiquan, S. Polen, C. M. Hadad, T. V. RajanBabu and J. D. Badjić, J. Am. Chem. Soc., 2016, 138, 8253-8258.

8 C. Bravin, G. Mason, G. Licini and C. Zonta, J. Am. Chem. Soc., 2019, 141, 11963-11969.

9 D. Zhang, B. Bousquet, J. C. Mulatier, D. Pitrat, M. Jean, N. Vanthuyne, L. Guy, J. P. Dutasta and A. Martinez, J. Org. Chem., 2017, 82, 6082-6088.

10 S. A. Ikbal, C. Colomban, D. Zhang, M. Delecluse, T. Brotin, V. Dufaud, J. P. Dutasta, A. B. Sorokin and A. Martinez, Inorg. Chem., 2019, 58, 7220-7228.

11 D. Zhang, A. Martinez and J. P. Dutasta, Chem. Rev., 2017, 117, 4900-4942.

12 (a) J. Canceil, A. Collet, J. Gabard, G. Gottarelli and G. P. Spada, J. Am. Chem. Soc., 1985, 107, 1299-1308; (b) O. Perraud, P. DimitrovRaytchev, A. Martinez and J. P. Dutasta, Chirality, 2010, 22, 88; (c) Ł. Szyszka, P. Cmoch, A. Butkiewicz, M. A. Potopnyk and S. Jarosz, Org. Lett., 2019, 21, 6523-6528.

13 (a) C. M. Moore, D. A. Quist, J. W. Kampf and N. K. Szymczak, Inorg. Chem., 2014, 53, 3278-3280; (b) E. W. Dahl, H. T. Dong and N. K. Szymczak, Chem. Commun., 2018, 54, 892-895.

14 (a) W. T. Eckenhoff and T. Pintauer, Inorg. Chem., 2007, 46, 5844-5846; $(b)$ W. T. Eckenhoff, S. T. Garrity and T. Pintauer, Eur. J. Inorg. Chem., 2008, 563-571.

15 S. C. Bete, C. Würtele and M. Otte, Chem. Commun., 2019, 55, 4427-4430.

16 L. You, G. Pescitelli, E. V. Anslyn and L. Di Bari, J. Am. Chem. Soc., 2012, 134, 7117-7125. 